Exploring Female Involvement in Acts of Terrorism and Mass Shootings: A Systematic Review

Nicholson, D., \& Allely, C. S.

Danielle Nicholson. Honorary Researcher, School of Health Sciences, University of Salford, Manchester, England and Assistant Psychologist in Psychiatric Intensive Care, Manchester, England.

Clare S. Allely. Reader in Forensic Psychology, School of Health Sciences, University of Salford, Manchester, England and affiliate member of the Gillberg Neuropsychiatry Centre, Sahlgrenska Academy, University of Gothenburg, Gothenburg, Sweden. 


\begin{abstract}
The primary objective of the present systematic review was: (1) To explore the current literature which assesses the incidence of completed or attempted mass shooting events in which a female party acted either alone or as an accomplice; (2) Explore the involvement of females in the planning or execution of acts of terrorism; (3) Evaluate the pathology of females involved in these acts of extreme violence; (4) Highlight any gender-specific pathological and environmental risk factors associated with the planning or completion of mass shooting, spree killing, or terrorist attack events.
\end{abstract}

Using the 27-item PRISMA guidelines (Moher, Liberati, Tetzlaff \& Altman, 2009), the present systematic review explored peer reviewed literature published between 1908 and September 2020 using six databases [SalfordUniversityJournals@Ovid; Journals@Ovid Full Text; APA PsycArticles Full Text; APA PsycExtra; APA PsycInfo; Ovid MEDLINE(R)], in addition to conducting a grey literature search on 'Google Scholar' using specific search terms, predetermined following use of the PICO framework.

Findings of the review did identify several distinguishing characteristics exclusive to females allied to terror organisations; including lower levels of extremism and religious ideology, lower age of radicalisation, higher levels of education than currently hypothesised and the significance of relational affiliation with extremist causes. The identification of distinguishing characteristics such as lower age of radicalisation, in addition to lower levels of extremism amongst females allied to terrorist groups is argued to present an opportunity for anti-terror interventions. Moreover, these findings develop our current understanding by offering an alternative to the current view that females involved with terrorist organisations, particularly those related to jihadi-inspired terrorism, do so out of the desire to gain financial and educational reward.

While the synthesis of descriptive characteristics relating to female terrorists was achieved, data relating to female mass shooters was scant and relied upon case study review and discussion. As a result, identification of precipitating psychopathological and environmental triggers was difficult, however, there does appear to be a higher proportion of female mass shooters targeting current or previous places of employment, disproportionately compared to male mass shooters. Additionally, the inclusion of case study discussion enabled an observation that females are more likely to be in contact with the police prior to undertaking such acts of violence. As such, although the current literature available for academic scrutiny of this phenomenon is scant, the above finding does develop our current understanding and offer an opportunity for intervention.

Key Words: Females; Woman; Women; Mass Shooters; Mass Murder; Gender; Mass Killing Events; Spree Killing; Terrorism; Lone-actor Terrorism; Extreme Violence. 

Female involvement in acts of terrorism and mass shooting events is a relatively unstudied phenomenon (Jacques \& Taylor, 2009; Turner, 2016; Wickham et al., 2020). Currently, the Federal Bureau of Investigation (FBI) has two classifications underpinning definitions of acts of terrorism. The first being International Terrorism, which is defined as "Violent, criminal acts committed by individuals and/or groups inspired by or associated with, designated foreign terrorist organisations or nations", the other being Domestic Terrorism, defined as "Violent, criminal acts committed by individuals and/or groups to further ideological goals stemming from domestic influences, such as those of a political, religious, social, racial or environmental nature" (Federal Bureau of Investigation, 2021). Although previous research has found that females acting either alone or as an accomplice account for only $12 \%$ of completed terror events (Gonzalez et al., 2014), the relatively few studies conducted to date have suggested that the rate of female involvement in such acts is accelerating (Laster \& Erez, 2015; Turner, 2016), particularly among female terrorists that are allied to extremist organisations (Wickham et al., 2020).

As such, efforts to understand the perpetuating factors that have allowed female acts of extreme violence to increase in recent decades largely rely on theoretical discussion and case study examination (e.g., Katsavdakis et al., 2011). This presents several issues in terms of our understanding of this phenomenon. For example, theoretical discussions can unintendedly include stereotype and bias based upon our understanding of female capacity and desire to undertake such acts of violence. Moreover, theories depend on our perceptions that are moulded in our respective societies and cultures; in addition to our own experiences and values (Jacques \& Taylor, 2012). Undoubtably this raises questions relating to the ecological validity and the reliability of cross international hypothesis, particularly in relation to the drivers behind participation in organised terror (Cunningham, 2007; Wickham et al., 2020).

This presents a potentially serious deficiency, particularly when formulating hypotheses surrounding the female demographic in organisations where our understanding of the cultural, societal and religious or political extremism driving such acts is formed predominantly by narratives depicted in mainstream media (Wickham et al., 2020). An example of this in play can be showcased by our misconceptions of female passivity in jihadi-inspired terrorism, that have driven the belief among counterterror organisations that females could not climb the hierarchy within terror organisations; and therefore not pose a direct risk of violence to the public (Cunningham, 2007). As such, this oversight has allowed, with particular reference to Al-Qaeda, a strategic advantage to such organisations who now use females increasingly for suicide missions; with equal frequency now to radicalised male counterparts (Capezza \& Stephenson, 2020). Additionally, case studies have shown that females are now recruited to aid in the building of explosive devices (Cunningham, 2007), which under current narratives of radical Islamism, show a moving away from traditionally understood values when it can increase the efficacy of the extremist cause.

Perhaps even less understood than females involved in terrorist organisations is the phenomenon of females completing or planning mass shooting events. Mass murder, and thus mass 
shooting involves multiple victims; resulting in at least four fatalities, in geographically near locations within a short time frame (Federal Bureau of Investigation, 2008). Although there are several different definitions of mass murder; which results in inconsistent rates of such incidents being cited and reported in literature, there were nearly as many mass murder events as there were days in the year in 2015 (Beckett, 2015). Despite limitations with the definition of mass murder; such as narrowly defining where the event must take place and the number of fatalities, various studies have shown that mass murder, and more specifically mass shooting events have dramatically increased in the last decade (e.g., Harvard School of Public Health, 2016; Fox \& Fridel, 2017; Björkqvist, 2018).

While there is a clear gender disparity in the rates of such attacks; with females only accounting for $4 \%$ of cases (Schildkraut \& Elsass, 2018), as with females allied to extremist organisations, the rate of female mass shooters has significantly increased over the past three decades (Gurian, 2018; Wickham et al., 2020). Again, the current literature evaluating the precipitating, motivating and environmental variables that lead up to such events is based upon case study discussion, and therefor direct comparison between the male and female demographic is yet to be achieved. Although women make up such a small proportion of the perpetrators, empirical research to identify gender specific contributory factors and warning behaviours salient to an attack must be achieved in order to minimise risk in these mostly preventable events (Gonzales et al., 2014).

\section{Present Review}

As an effort to bridge the gap in research that investigates female involvement in terrorism and mass shooting events, the primary objective of the present systematic review is to: (1) To explore the current literature which assesses the incidence of completed or attempted mass shooting events in which a female party acted either alone or as an accomplice; (2) Explore the involvement of females in the planning or execution of acts of terrorism; (3) Evaluate the pathology of females involved in these acts of extreme violence; (4) Highlight any gender-specific pathological and environmental risk factors associated with the planning or completion of mass shooting, spree killing, or terrorist attack events.

It is hoped that by examining female involvement in acts of extreme violence, by both mass shooting events and attacks allied to terrorist organisations, that our understanding for the propensity for extreme violence posed by females is developed. Moreover, by examining both forms of extreme violence, the current review aims to highlight any overarching narratives or stereotypes that may have affected our current understating of the risk posed by female assailants. As such, this could develop our knowledge further, and may offer an explanation as to why there have been missed opportunities by enforcement organisations in both the prevention of mass shooting and terrorist attack events completed by females. 


\section{Method}

Protocol and Registration

We did not register the protocol for this review.

\section{Eligibility Criteria}

In the first instance, papers that included an investigation into the trends of female involvement in terrorist activity, for example in the planning and/or completion of a terrorist attack; either as part of a wider organisation or alone were deemed as appropriate. As such, any peer reviewed paper that referred to environmental or pathological precipitating factors associated with the risk of female involvement in such events were screened for relevance. Additionally, due to the relatively rare occurrence in which female assailants are identified as significant in completed or attempted mass shooting or spree killing events, it was decided that the inclusion criteria would adopt a more inclusive than exclusive approach. For example, some of the studies identified and included in the review did not specifically examine characteristics exclusive to female mass shooters, however evaluation of gender differences was discussed and were therefore deemed as valuable to this review (e.g., Brugh et al., 2019; Gurian, 2018). Although inclusion of such studies could be determined as posing a risk to the reliability of the findings of this review, the limited data available which specifically evaluates the current demographic highlights the need to evaluate all relevant literature, even if the primary goal of such studies was not to focus on female assailants.

\section{Information Sources}

Six online access bibliographical databases [SalfordUniversityJournals@Ovid; Journals@ Ovid Full Text; APA PsycArticles Full Text; APA PsycExtra; APA PsycInfo; Ovid MEDLINE(R)], were searched for titles in order to identify studies which evaluated characteristics of female mass shooters, spree killers and females involved in terrorist acts, in addition to studies which discussed gender differences in such events. The search included all peer-reviewed publications available from 1908 to September 2020. The flowchart seen below outlines the process of eliminating non-relevant papers, using current PRISMA Guidelines (see Figure 1). Duplicates $(n=192)$ were excluded prior to the retrieval of references.

\section{Search}


Searches were originally conducted on $10^{\text {th }}$ September 2020. The following search criteria were entered into all six of the databases: [Female* OR Woman OR Women OR Gender OR "Gender differenc*"] AND ["Mass Shoot*” OR "Spree Kill*” OR "Mass Murder*” OR Terror* OR Murder* OR Attack*] AND [Pathology OR Warning OR "Red Flag*" OR "Mental Illness*”] AND ["Future Viole*" OR "Risk of Radical*"]. Use of all terms returned five potentially relevant articles following deduplication. As such, permutations that were entered under the comparison/control and outcome measure criteria were removed to broaden the search. Following this, 597 potentially relevant citations were found after deduplication; a brief screening process using title, abstract, key word and a summary review identified that 73 articles required further exploration, with the remaining 524 articles being excluded.

Additionally, various permutations of female mass shooters, female spree killers and female involvement in terror attacks were entered into Google Scholar, for instance: ["Mass Shooting*" AND Female* OR "Spree Killing” AND Women OR "Mass Murder" AND Women OR Terroris* AND Women]. For each search that was entered on Google Scholar, a minimum of 10 pages of results were evaluated by reading through the title of and caption for each study, along with highlighted relevant words and sentences within the text. As a result, seven papers were noted as being potentially relevant, and so a review of the abstract, in addition to references contained within the papers were screened for inclusion eligibility. Abstracts for each reference were obtained and screened using the following eligibility criteria:

\section{Inclusion Criteria:}

1. Papers that explored acts of extreme violence (e.g., spree killing, mass killing or mass shooting events, terroristic acts; serial or multiple homicide) perpetrated by females.

2. Papers that explored the difference between male and female perpetrators of extreme violence (e.g., spree killing, mass killing or mass shooting events, terroristic acts; serial or multiple homicide)

3. Peer reviewed case studies exploring female assailants of extreme acts of violence (e.g., mass killing or shooting events and acts of terrorism).

4. Studies that explored the trends in female involvement in terrorist attacks, either acting alone or as part of a wider organisation.

\section{Exclusion Criteria:}

1. Papers not published in English

2. Dissertations, posters, conference proceedings, letters to the editor/editorials

3. Book reviews 
Screening:

In the first instance, papers were excluded which:

1. Did not include an investigation into mass shooting, spree killing or terrorism with reference to the female demographic or gender specific risk factors for complicity in acts of extreme violence.

2. Investigated serial killing or serious violent offences committed by women that resulted in death, for example during Intimate Partner Violence (IPV).

However, as per The Department of Justice Mass Shooting Database | The Violence Project, (2020), the number of victims/fatalities when a mass killing event is perpetrated by a female is noted as being significantly lower comparatively to the same events completed by male counterparts. As such, there is the possibility that attacks carried out by females do not fall under current definitions despite intention and planning, and therefore reliable identification of cases and trends relating to this demographic is problematic and has consequences for the clarity in current literature (Campion, 2020). As a result, papers which investigated attempted murder by women where the offense took place in a public space with multiple intended victims, in addition to using an offensive weapon; defined by the Collins Dictionary of Law as "any article made or adapted for use for causing injury to a person or intended by the person having it" (Stewart, 2006), were screened.

In total 583 articles were excluded from the review. A significant amount of such papers focussed upon femicide and females involved in serial killing, filicide, and murders in the context of Intimate Partner Violence. As such these were deemed inappropriate for the purpose of the review. Both authors (DN and CSA) reviewed all the returned articles from the search to see if they meet this reviews exclusion and inclusion criteria. Both authors were in agreement with the remaining 14 articles identified following a thorough screening process as being relevant for this review. 

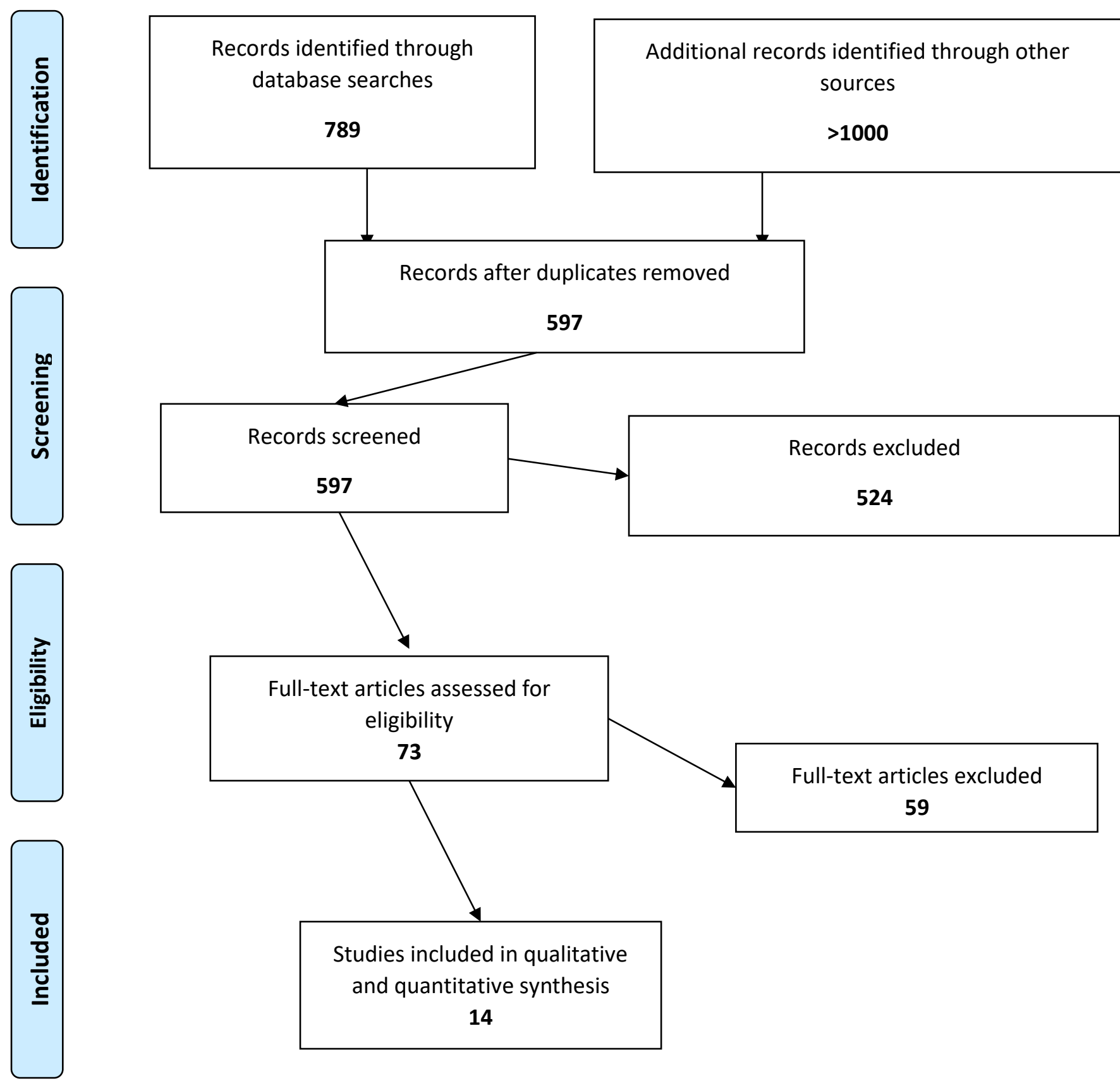


\section{Results}

A total of 14 articles were identified and meet the inclusion criteria of the present review. Specifically, 13 discussed female involvement in terrorist organisations (Messing \& Heeren, 2004; Blee, 2005; Nacos, 2005; Cunningham, 2007; Jacques \& Taylor, 2009; Jacques \& Taylor, 2012; Gonzalez et al., 2014; Cruise, 2016; Sawicki, 2016; Gurian, 2018; Brugh et al., 2019; Felthous et al., 2019; Wickham et al., 2020) and one discussed female mass shooters (Katsavdakis et al., 2011). Only four of these studies (Jacques \& Taylor, 2009; Jacques \& Taylor, 2012; Gurian, 2018; Brugh et al., 2019) empirically investigated the individual characteristics and demographics associated with females who either planned or completed such acts. The remaining papers were either reviews, theoretical evaluations or case study discussions of female involvement in acts of extreme violence.

Female Involvement in Terrorist Organisations: Comparative Characteristics based on Gender

Two studies were identified in this review which used comparative analysis to explore female involvement in terrorist organisations compared to male counterparts (Jacques \& Taylor, 2012; Brugh et al., 2019). In the first, Jacques and Taylor (2012), analysed data on 222 female terrorists with a control of 269 male counterparts, associated with extremist organisations from the middle east, Europe, Asia and Latin America. Data was retrieved from secondary sources (e.g., books, newspaper articles, internet sites, $\mathrm{PhD}$ theses), triangulated to increase reliability and then catalogued into discreet groups, organising male from female offenders based upon the terrorist group each individual was associated with. Based on the data available for the study, several groups were identified. They included religious extremist organisations such as Al-Qaeda and Al-Qaeda in the Islamic Maghreb; animal and environmental rights groups including the Animal Liberation Front, Earth First, and the Earth Liberation Front. The study also included political extremist organisations such as the Irish Republican Army, Popular Front for the Liberation of Palestine, and the Communist Party (in both Telangana and Nepal).

Following comparative analysis of eight variables (age, marital status, employment history, educational level, immigration status, criminal history, family history of activism and organisation) results suggest that across organisations there are specific risk factors associated with females who become actively involved with and commit acts of terror. For example, females were significantly less likely to be employed at the time of offending $(p<.01)$, were less likely to be religious converts, less likely to be immigrants and more likely to be widowed or divorced $(p<.016)$. The mean age of females within the sample was 22.6 years $(S D=7.43)$ which did not differ significantly to the mean age of males $(\mathrm{M}=22.2$ years, $\mathrm{SD}=6.12$ ). While the ages of those who had completed or attempted attacks did not differ significantly, the age of females when first introduced to extremist organisations was significantly 
lower than males. Both males and females in the sample had similar levels of education, with a majority completing both secondary and tertiary education. Importantly, among the female group, over one third had familial connections to the terrorist organisation; strengthening previous research which suggests that relationships form a catalyst for the involvement of females within such groups (Jacques \& Taylor, 2009).

In the second paper, Brugh and colleagues (2019) conducted a quasi-experimental study designed to compare characteristics of females and makes involved in Jihadi-inspired terrorism. By accessing data publicly available through the Western Jihadism Database, descriptive demographical characteristics of 405 women involved in Jihadi-inspired terrorism (with variables such as criminal history, organisational involvement, plot involvement and foreign fighting being explored), formed the basis for comparative analysis of a subgroup of the females (female $n=272$, males $n=266$ ). Results found that while there was no significant difference between the males and females in terms of age at radicalisation, there were differences in terms of year of birth $(p<.01)$. Post hoc comparisons showed that males were proportionally more likely to be born between 1983 and 1990, while females were significantly more likely to be born after 1990. Such findings could be deduced as highlighting an increase in females being recruited to terrorist organisations in the last three decades, a hypothesis which has been noted in previous research (e.g., Cunningham, 2007). Despite this, there is an inconsistency between findings in relation to age of radicalisation, between the two papers reviewed which examined this characteristic (e.g., Brugh et al., 2019; Jacques \& Taylor, 2012). One potential reason for the lack in clarity in this finding could be the wide range of organisations examined in Jacques and colleagues, whereas Brugh and colleagues focused only on organisations allied to extremist jihadism.

Additionally, Brugh and colleagues found that educational levels did not significantly differ by gender $(\mathrm{p}<.054)$ and that females were significantly less likely to be employed compared to their male counterparts, further supporting previous findings (e.g., Jacques \& Taylor, 2012). However, there was some difference between these two studies in terms of criminal history. Men were significantly more likely to have a criminal history prior to radicalisation, compared to females $(\mathrm{p}<.001)$, whereas in Jacques and colleagues (2012) there was no clear evidence of offending history for either gender. Despite this difference the majority of both males and females, examined in both papers, did not have a criminal history prior to involvement in terrorist organisations.

Brugh and colleagues also found that roles within terrorist organisations differed significantly, with women more likely to be actively involved with the recruitment aspect of the organisation, compared to males who did not play a significant role in this area. In terms of completed or planned attacks, the vast majority of male members were linked to at least one plot of attack, compared to just over one third of females. Despite females being less likely to be involved in plots to complete violent attacks overall, when narrowing the lens onto attempts of foreign fighting, females where significantly more likely to be involved with $(p<.001)$ and successfully complete foreign fighting attempts $(p<$ 
.027). The authors discuss that this could, in part, be due to female assailants being less likely to be suspected of such attacks and therefore be apprehended. See Table 1 for a summery of findings relating to characteristics and gender.

Table 1: Comparative Characteristics based on Gender

\begin{tabular}{|c|c|c|c|}
\hline Variable & Males & Females & Source \\
\hline \multirow[t]{2}{*}{ Age at time of Attack } & $M=22.2, S D=6.12$ & $M=22.6, S D=7.43$ & Jacques et al., (2012) \\
\hline & - & - & Brugh et al., (2019) \\
\hline \multirow[t]{2}{*}{ Year of Birth } & - & - & Jacques et al., (2012) \\
\hline & $1983-1990$ & After $1990 * *$ & Brugh et al., (2019) \\
\hline \multirow[t]{2}{*}{ Employment History } & More Likely & Less Likely** & Jacques et al., (2012) \\
\hline & More Likely & Less Likely* & Brugh et al., (2019) \\
\hline \multirow[t]{2}{*}{ Educational Level } & Secondary, Tertiary & Secondary, Tertiary & Jacques et al., (2012) \\
\hline & Secondary, Tertiary & Secondary, Tertiary & Brugh et al., (2019) \\
\hline \multirow[t]{2}{*}{ Immigrants } & More Likely & Less Likely & Jacques et al., (2012) \\
\hline & - & - & Brugh et al., (2019) \\
\hline \multirow[t]{2}{*}{ Religious Converts } & More Likely & Less Likely & Jacques et al., (2012) \\
\hline & - & - & Brugh et al., (2019) \\
\hline \multirow[t]{2}{*}{ Offending History } & No Clear Evidence & No Clear Evidence & Jacques et al., (2012) \\
\hline & More Likely & Less Likely*** & Brugh et al., (2019) \\
\hline \multirow[t]{2}{*}{ Role in Organisation } & - & - & Jacques et al., (2012) \\
\hline & Planning of Attacks & Recruitment & Brugh et al., (2019) \\
\hline \multirow[t]{2}{*}{ Foreign Fighting } & - & - & Jacques et al., (2012) \\
\hline & Less Likely & More Likely*** & Brugh et al., (2019) \\
\hline \multirow[t]{2}{*}{ Marital Status } & Married & Widowed/Divorced* & Jacques et al., (2012) \\
\hline & - & - & Brugh et al., (2019) \\
\hline
\end{tabular}

Significance level: $p=<.05^{*}, p=<.01 * *, p=<.001 * * *$

Characteristic Comparison based on Organisation and Gender

Two papers were identified in this review which explored female involvement in terrorist organisations based on organisation (Blee, 2005; Gonzalez et al., 2014). In the first, Gonzalez and colleagues (2014) used data from the U.S Extremist Crime Database (ECDB) to examine homicides by far-right extremists, and to investigate arsons and bombings completed by environmental and animal rights 
extremist groups in the United States. Results suggest that environmental influential factors differ between men and women. For example, religious extremism was non-present in female domestic terror attackers/co-conspirators compared to their male counterparts within far-right organisations. It was found that extremist Christian ideology motivated engagement with such organisations among men, but not women. Rather women were mobilised more often by relatives, friends or due to 'relative deprivation' - particularly among females from lower socio-economic backgrounds. Descriptive analysis of female characteristics among far-right groups highlight that most women were dating or cohabiting $(64.3 \%)$ compared to $21.4 \%$ being single and $14.3 \%$ being married. Additionally, only $21.4 \%$ of the women within far-right data included in the study had children, and 14.3 were pregnant at the time of arrest/attack. The ages of females within such groups ranged from 16-71 among those who held ideological extremist views, and 16-26 among those in the same organisations who did not have extremist views. Finally, those with a prior criminal history only accounted for $7.15 \%$ of cases (Gonzalez et al., 2014).

Gonzalez and colleagues (2014) also found that, in contrast to women involved in far-right extremism, there were some differences among females who engaged in ideologically motivated violent attacks allied to ECO/ALF groups. Firstly, the age ranges of those involved were significantly less spread at between 18-47. Data on the relational status of these women was less complete, but analysis of the partial data available shows that only $18.8 \%$ were married, dating or cohabiting. Similarly, women involved with such groups were less likely to have children with only $6.3 \%$ being mothers. Finally, females associated with ECO/ALF groups were more likely to have a prior criminal history at $12.5 \%$. There were no women who acted alone in either far-right organisations or ECO/ALF groups. However, female co-conspirators in far-right groups who held extremist religious beliefs and had relational ties to the group accounted for $42.9 \%$ of the attacks involving women, with this number rising to $80 \%$ when a female friend was involved in the group. Due to limited data on females with ECO/ALF groups, a direct comparison addressing any difference between relational involvement was unavailable. Despite this, the data available for analysis showed that all women involved in attacks allied to environmental and animal rights organisations held extremist views, which was in contrast to females within the far-right groups (Gonzalez et al., 2014). Lastly, in terms of gender comparison of those involved in homegrown terrorism in the US, Gonzalez and colleagues found that females involved with far-right terrorist attacks were on average 10 years younger than males of the same group at the time of attack, were less likely to have a criminal history, equally as likely to be employed but less likely to hold a tertiary education. Of this group, females accounted for $10 \%$ of the involvement in violent incidents, and usually completed only one attack, whereas males were more likely to commit repeated offenses. This is in contrast to men and women involved in ECO/ALF groups, who were equally likely to carry out multiple attacks, and be similar in age (Gonzalez et al., 2014). 
In the second paper, Blee (2005) explored differences in organisational roles based on gender, using case study discussion of female involvement in racial violence associated with the major organised white supremacist groups in the United States: the Ku Klux Klan, White Power Skinheads, and the neo-Nazis between 1990-2003. Highlighted was that unlike male counterparts, female's involvement was generally indirect (e.g., the involvement of Hally Dartez in the Ku Klux Klan 'cross burning') or was used as a tactical aid to legitimise racial terrorism by creating a perception of normalcy. The author highlighted the disjunction in the rates of females playing parts in the recruitment process compared to the completion of violent acts in terrorist organisations around the world, not just of those seen in homegrown terrorist organisations within the United States. Interestingly of the case studies discussed by Blee, the females involved were all aged between 18 and 35 years, whereas the male counterparts noted in specific incidents were aged between 38-47. Although quantitative analysis of this difference was not completed, such incidents showcase that over time there is a distinct difference between not only the roles within groups but also the age of assailants based on gender at the time of critical incidents being completed. See Table 2 for a summary of findings related to characteristics based on organisation and gender. 
Table 2: Characteristics based on Organisation and Gender

\begin{tabular}{|c|c|c|c|c|c|c|}
\hline \multirow[t]{2}{*}{ Variable } & \multirow{2}{*}{$\begin{array}{c}\text { Far-Right } \\
\text { Males }\end{array}$} & \multicolumn{3}{|c|}{ Far-Left } & \multicolumn{2}{|l|}{ Source } \\
\hline & & Females & Males & Females & & \\
\hline Age at Attack & $\begin{array}{c}10 \text { years older } \\
\text { on average }\end{array}$ & $16-71$ & $\begin{array}{c}\text { No significant } \\
\text { difference }\end{array}$ & $18-47$ & $\begin{array}{l}\text { Gonzalez et } \\
\text { al., (2014) }\end{array}$ & \\
\hline & $38-47$ & $18-35$ & $38-47$ & $18-35$ & Blee (2005) & \\
\hline $\begin{array}{c}\text { Repeated } \\
\text { Attacks }\end{array}$ & Yes & No & Yes & Yes & $\begin{array}{l}\text { Gonzalez } \\
\text { al., (2014) }\end{array}$ & et \\
\hline $\begin{array}{c}\text { Employment } \\
\text { History }\end{array}$ & Yes & Yes & Yes & Yes & $\begin{array}{l}\text { Gonzalez } \\
\text { al., (2014) }\end{array}$ & et \\
\hline $\begin{array}{l}\text { Criminal } \\
\text { History }\end{array}$ & More Likely & $7.15 \%$ & $\begin{array}{l}\text { Equally } \\
\text { Likely }\end{array}$ & $12.5 \%$ & $\begin{array}{l}\text { Gonzalez } \\
\text { al., (2014) }\end{array}$ & et \\
\hline $\begin{array}{c}\text { Extremist } \\
\text { Views }\end{array}$ & More Likely & Less Likely & Present & Present & $\begin{array}{l}\text { Gonzalez } \\
\text { al., (2014) }\end{array}$ & et \\
\hline $\begin{array}{l}\text { Religiously } \\
\text { Motivated }\end{array}$ & $\begin{array}{l}\text { Extremist } \\
\text { Christian } \\
\text { Ideology }\end{array}$ & Less Likely & No & No & $\begin{array}{l}\text { Gonzalez } \\
\text { al., (2014) }\end{array}$ & et \\
\hline Marital Status & $\begin{array}{l}\text { Majority } \\
\text { Married }\end{array}$ & $\begin{array}{c}85.7 \% \\
\text { Married or } \\
\text { Cohabiting }\end{array}$ & Unclear & $\begin{array}{c}18.8 \% \\
\text { Married or } \\
\text { Cohabiting }\end{array}$ & $\begin{array}{l}\text { Gonzalez } \\
\text { al., (2014) }\end{array}$ & et \\
\hline Children & Not Clear & $\begin{array}{c}21 \% \text { Mothers } \\
14.3 \% \\
\text { Pregnant }\end{array}$ & Not Clear & $6.3 \%$ Mothers & $\begin{array}{l}\text { Gonzalez } \\
\text { al., (2014) }\end{array}$ & \\
\hline $\begin{array}{c}\text { Connection to } \\
\text { Cause }\end{array}$ & Not Clear & $\begin{array}{l}\text { Relational } \\
\text { Ties }(80 \%)\end{array}$ & Not Clear & Not Clear & $\begin{array}{l}\text { Gonzalez } \\
\text { al., (2014) }\end{array}$ & \\
\hline
\end{tabular}


Motivation to Engage with Extremist Organisations

Three studies were identified in this review which explored motivation in relation to female involvement in terrorist organisations (e.g., Jacques \& Taylor, 2009; Sawicki, 2016; Wickham et al., 2020).

In the first, Jacques and Taylor (2009) focussed upon motivational factors associated with terrorism using 54 publications that addressed female terrorism involvement. The authors analysed and grouped motivational affecters into five distinct groups: (1) Social - this includes gender equality, educational/occupational needs, humiliation and repression within respective communities; (2) Personal - this includes psychological distress, financial anxiety, and social isolation; (3) Idealistic this includes religious extremism, nationalism, commitment to cause, and martyrdom; (4) Key Event - this includes the loss of a loved one, specific humiliation, and displacement; (5) Revenge - this includes vengeance and anger. Findings of the review concluded that of the cases identified, social drivers were the most common catalyst for undertaking a terror attack (34 incidents) followed by personal attributes including psychological distress prior to the attack (18 incidents). Attacks that were carried out with the sole motivator being ideology were cited in 15 cases, shortly followed by cases that identified a key event such as the loss of a loved one or a specific humiliation (12 cases). Very few known cases were identified as being primarily motivated by revenge, with four cases being noted in the review.

With the high proportion of female involvement in planned or completed terror attacks being attributed to social factors, Jacques and Taylor (2009) then discussed environmental enablers identified through literature content analysis and found that misconceptions surrounding female involvement aids in the internal strategy of organised terror groups. Such misconceptions include unfounded beliefs that female involvement is rare and without personal agency, meaning that fewer resources are utilised in the investigation of female involvement. Additionally, the authors discuss perceptions of females involved with extremist groups and note that there is a belief amongst counter-terror organisations that female terrorists take passive and non-violent roles within organisations, despite growing trends which suggest the contrary (Wickham et al., 2020). As such the authors note that this has created a known strategic advantage to extremist groups and aided in the further recruitment to such organisations, enabling increasing trends in completed suicide attacks by female parties (Jacques \& Taylor, 2009).

Similarly, a narrative review by Sawicki (2016) discussed female involvement in suicide bombings as being a strategic motivator of the organisation, noting that focusing upon individualistic motivational variables offers a minimised view of the impact of female participation in such acts. Sawicki showcases the 2015 suicide bombing attack in Baga Sola, whereby two females and two children completed the attack, and surmises eight tactical advantages gained following the event, which 
are stipulated to have increased the organisational efficacy of Islamist extremist group Boko Haram. Sawicki argues that the use of females in suicide bombings is a tactical strategy to gain notoriety, perceptions of power and aims to increase shock, fear and participation. Sawicki stipulates that such motivations run alongside individualistic precipitating factors; such as poverty and personal agency, and is intrinsically relevant and directly related to globally understood female roles and stereotypes within society; that are irrespective of religious belief, culture and political affiliation. As such, he notes that the use of females, and in some cases children, as being frontline fighters for a cause is more likely to garner public attention and thus directly increase the potential for further recruits to the cause, are less likely to be anticipated and thus more likely to be successful (Sawicki, 2016).

Lastly, Wickham and colleagues (2020) used a psychological perspective using Vrooms Expectancy Theory of Motivation (1964) to discuss the environmental and psychological underpinnings of female extremist activism. With a focus of gender stereotyping research, the authors offered discussion as to why female involvement continues to be overlooked in counter-terror efforts. Using psychological theory and previous cases involving female involvement in extremist organisations, four common themes of motivation were detailed describing how and why females become involved in terrorism. The first theme centres on ideology and the discussion focussed on cases particular to Palestinian women whose primary motivation is political, such as in the Ayat Akras case, where a female detonated a bomb in a suicide attack. Previous writings by Akras suggest the motivation for the attack was to fight alongside militants in the war for statehood. As such, this theme and the case described showcases a misconception that females who complete terror attacks lack personal agency and the ability to present as violent without coercion.

In the second theme of personal/situational circumstance, cases are discussed with a focus on middle eastern women who completed terror attacks. The authors argue that of these women, motivation to complete suicide missions is to enable them to move beyond their status within society. Discussing the case of Malika el Aroud, the authors note her disclosure that radicalisation came after facing the xenophobia she experienced due to her status as an immigrant. She expressed that her involvement with the organisation provided her with an identity and improved social status. As such, this theme and the case discussed underlined a current myth in female terrorism research that revenge attacks are primarily a reaction to losing a family member, particularly a spouse, in extremist conflict.

The third theme detailed is empowerment, which the authors note is an extension of personal and situational circumstance. Prior to completing suicide bombings, Palestinian women reported feeling empowered as they would be perceived as being equals in the nationalist fight, rather than just care givers or educators. Wickham and colleagues linked this rational to females involved in terrorist organisations such as Al-Qaeda, where the role of women in the organisation is predominantly believed to produce sons and educate them about the cause and as such, the rate of females committing suicide bomb attacks has risen dramatically and now constitutes $50 \%$ of all suicide attacks (Cunningham, 2007). 
An important overarching component of the first three themes discussed is the presence of choice and desire, and the use of personal agency to complete acts of extreme violence in female terrorists. This current understanding is in contrast to widely held beliefs deriving from societal expectations and norms of behaviour that stipulate that females are less capable of committing violence than men. The authors argue that media portrayals of female extremists and of religious ideologies; particularly in Islam where females are described as unwillingly submissive in western conversation, perpetuate this understanding and inhibit counterterror efforts (Cunningham, 2007). Although arguments remain regarding the confounding environmental factors that illicit such desires in female terrorists; such as the need for education, financial support and political freedom, the evidence that acts of extreme violence is voluntary and desired in some cases aids in untangling a dangerous misconception (Wickham et al., 2020).

The fourth theme described by Wickham and colleagues' is argued to be the most widely accepted pathway into violent extremism among females. The theme describes involutory enlistment, where females are coerced or forced into joining the cause. Citing several cases, details of how females are frequently coerced into martyring by male relatives who wish to increase their status in the terrorist organisation were discussed. As such, the authors note that the fear of social rejection and shame upon the family emotionally blackmails some females into committing suicide bombings. Additionally, Wickham and colleagues cite cases amongst Iraqi women, where male extremist group members rape females as a strategy to recruit them as suicide bombers. Emphasis on the status of a woman following rape is highlighted as being a particular issue, culturally, where blame and shame of the attack is placed with the female. As such, enlistment by this mean offers females an avenue to address trauma and escape the social rejection through the means of suicide bombings; in a culture where suicide under Islam is strictly forbidden. As such, the female is offered a choice between death as a martyr or societal shame and rejection (Wickham et al., 2020). See Table 3 for a summary of findings relating to motivational affecters in female terrorists. 
Table 3: Factors Associated with Motivation to Engage in Terrorist Organisations amongst Females

\begin{tabular}{|c|c|c|}
\hline Variable & Prevalence & Source \\
\hline \multirow[t]{2}{*}{ Educational or Financial Needs } & 34 of 54 cases & Jacques \& Taylor (2009) \\
\hline & 1 case study & Wickham et al., (2020) \\
\hline Psychological Distress and Illness & 18 of 54 & Jacques \& Taylor (2009) \\
\hline \multirow[t]{2}{*}{ Extremist Ideology } & 15 of 54 & Jacques \& Taylor (2009) \\
\hline & 1 case study & Wickham et al., (2020) \\
\hline Specific Loss or Humiliation & 12 of 54 & Jacques \& Taylor (2009) \\
\hline \multirow[t]{2}{*}{ Revenge } & 4 of 54 & Jacques \& Taylor (2009) \\
\hline & 1 case study & Wickham et al., (2020) \\
\hline $\begin{array}{l}\text { Gain Notoriety or Attention to } \\
\text { Cause }\end{array}$ & 1 case study & Sawicki (2016) \\
\hline Empowerment & 1 case study & Wickham et al., (2020) \\
\hline $\begin{array}{l}\text { Involuntary Enlistment and } \\
\text { Coercion }\end{array}$ & Unclear & Wickham et al., (2020) \\
\hline
\end{tabular}

Misconceptions and Myths surrounding Female Involvement in Terrorism

Four studies were identified in this review which discussed misconceptions and myths regarding female involvement in terrorist organisations (Nacos, 2005; Cunningham, 2007; Cruise, 2016; Wickham et al., 2020). In one review, Cunningham (2007) put forward 'The Six Counter Terrorism Deficiencies' which have enabled the acceleration and success of female perpetrated terror attacks; namely (1) The exploitation of incarcerated females, (2) Myths regarding the organisational structure of militant groups, (3) The role of technology in female activism, (4) Denial and deception regarding female involvement, 
(5) Tactical advantages of female activism being overlooked and (6) Culture and ideology misconceptions. Using publicly available case study material, incidents in the United States, Russia and Israel were analysed so that identification of issues relating to counterterrorism, and thus environmental enablers could be explored. Throughout the review, the authors highlight an unwillingness to 'exploit' or gain valuable information from females whose suicide missions failed, cataloguing 'missed opportunities' in counterterrorism. For example, current data as cited in Cunningham (2007) shows that there are 13 Palestinian women incarcerated following failed suicide bomb attacks, yet interrogation and investigation into their characteristics and pathway to violence has not been accessed. Similarly, $46 \%$ of the Moscow Theatre Hostage takers were female, of which the majority are now in custody. Despite this, access to gain insight into key enablers of terror involvement amongst this group has not been utilized. The author argues that the underpinning mechanism in this unwillingness is an intrenched view that female attackers are a rarity, and that they present a lesser risk due to an inability to climb the organisational hierarchy present in terrorist organisations. Highlighting the disparity between societal misconceptions, inaccurate narratives of female involvement in organised terror organisations, and the realities of modernising terrorist groups; who use such misconceptions as a strategic advantage, the authors showcases the incident of the first female bomb maker in Hamas in 2005.

In the second review evaluating the myths and misconceptions of female involvement in terrorist organisations, Cruise (2016) reviewed academic studies, government and non-profit agency studies and media characterisations of female terrorists. Cruise highlights a $15 \%$ increase in female participation in terrorist organisations, and a growing expansion of their roles within their respective organisations over the past two decades. Further, the author highlights triangulation of previous studies to showcase that $25 \%$ of all suicide bombing attacks are now completed by female assailants. By reviewing organisational differences between male and female terrorists, Cruise notes that while there are religious themes underpinning female activism, that female attacks over the last decade, up to 2016, are most prevalent in in secular and nationalistic causes, and are usually associated with leftist causes such as in the LTTE in Sri Lanka; the Chechen cause in Russia and Palestinian groups in conflict areas of Israel. Moreover, since 1985, direct female involvement in terror attacks accounts for $50 \%$ of all fatalities in Iraq, Israel, Lebanon, Chechnya, Sri Lanka, Morocco and Palestine, yet gender is not currently discussed in the 'Global Index Report 2014: Measuring and Understanding Terrorism' by the Institute for Economics and peace. Despite increasing rates of female terroristic activity, Cruise surmises the role of media portrayals in limiting the public and wider counter-terror organisations identifying and thus implementing tactical considerations to limit further growth and develop our understanding of female terrorists. By showcasing findings from a government national survey following the Moscow Theatre Attacks, the author points to media representation of the female perpetrators in being indicative of the results; where $84 \%$ of the public believed that the women were 
coerced or controlled by a male counterpart, with only $3 \%$ believing the females acted on their own free will.

Similarly, Nacos (2005) conducted a theoretical discussion of media depictions of female terrorists. Using case study material and critical review of media reports, the author highlights the difference in reporting style based on gender, the target population of viewing and the political agendas during the time of incident. Nacos argues that media depictions of female terrorists report in 'explanatory frames' to cue the reader/viewer, highlighting features that project societally accepted or politically desirable features of the event or assailant; obscuring other features that do not fit with the cultural norms or beliefs within a given target population. As such, the author argues that such reporting aids in widening the gap between stereotypically understood features of female terrorists and the reality of gender roles within terrorist organisations, which further undermines tactical considerations within counter terrorism (Nacos, 2005).

Psychopathology of Female Terrorists

Two papers were identified in this review which explored female involvement in terrorist organisations and mass murder (Felthous et al., 2019; Messing \& Heeren, 2004). Felthous and colleagues (2019) investigated psychological vulnerabilities associated with extreme violence among female terrorists. Using available data derived from interview accounts from family members of female suicide bombers, the authors note that depression, post-traumatic stress disorder, delusional disorders, in addition to perceptions of social stigmatisation were key contributory factors in females resorting to extremist violence. The authors gained further insight into the psychological drivers behind female completed suicide bombings by evaluating interview data from the husband of Wafa Idris, who completed a terror attack in 2002. Factors disclosed that were deemed as precipitating the attack include the loss of a child and a subsequent divorce that perpetuated Idris's battle with depression. Details of a worsening state of depression and voiced intentions of suicide were disclosed by Idris to her family members, in combination with the understanding of suicide being forbidden by Islam. As such, the husband explained that if one is wanting death, a Jihadist attack can allow this manner of death without bringing religious conflict.

Similarly, Messing and Heeren (2004) highlighted the importance of relational ties, family dynamics and environmental precipitating variables, such as poverty, among females who had been convicted of attempted or completed mass murders. Using data available through FBI archives and case study material, the authors highlight 13 variables that appear critical in the commissioning of such events. It was found that $57 \%$ of female assailants had been the victim of domestic violence, were disproportionately more likely to live in socioeconomically deprived areas, have previous involvement with mental health services and have sought professional assistance i.e., from their doctor, prior to 
completing or attempting acts of extreme violence. Additionally, social isolation of the perpetrator appears a significant pre-empting factor, with the loss of employment, the breakdown of significant relationships or the death of a loved one being sighted in numerous cases. Although such findings do appear to remain crucial in cases of extreme violence completed by females in the more recent past, the authors note limitations with identifying precipitating variables; noting sampling error, limited availability of data and reporting bias as being indicated in reducing reliability.

Female Mass Shooters

Only one paper was identified in this review which explored female involvement in mass shooting events. Katsavdakis and colleagues (2011) presented the case study of a female who completed a mass shooting attack on her previous place of work in 2006, before committing suicide. Using primary and secondary source material, the authors reconstructed the events leading up to the attack, in addition to exploring the offender's history. Findings of the investigations showed that the perpetrator suffered from a long history of mental illness, namely paranoid schizophrenia that had required frequent hospitalisations over the course of her lifetime. The female was 44 years old, Caucasian, not married and had no children. In a paradox to female suicide bombers, evidence of a long employment history was present. The female had a tertiary level of education; however, graduation of her degree was not completed. The offender also published volumes of her own newsletter titled "They Kill Jews and Niggers. The First Edition of the Racist Press - Volumn I-V", (2003). After review of her writings, the authors note a furthering into paranoid and delusional thinking, with the perpetrator hinting at future violent acts to avenge her perceived injustices particularly focussed upon her previous place of employment. The authors note that contrary to popular press, the perpetrator did not 'snap'. Instead, she completed a pathway into violence closer related to that seen in male mass shooters, where an effort to plan and execute an attack is developed over time in response to perceived injustices and grievance (e.g., Meloy et al., 2012). The female completed the mass shooting attack on her previous place of work, five years after her dismissal due arguably to her mental state. The authors stipulate this is also contrary to the populist belief that threat decreases overtime but is consistent with the paranoid and psychotic disorder symptoms seen in mass murderers; where rumination for months and sometimes years precipitates attacks.

\section{Discussion}

The lack in research that scrutinises the social, environmental and psychopathological precipitating factors salient to female involvement in terrorism and acts of mass shooting has inhibited meaningful discussion as to the best counter-terror strategies exclusive to females (Cunningham, 2007). As such, the primary focus of this systematic review was to (1) To explore the current literature which assesses 
the incidence of completed or attempted mass shooting events in which a female party acted either alone or as an accomplice; (2) Explore the involvement of females in the planning or execution of acts of terrorism; (3) Evaluate the pathology of females involved in these acts of extreme violence; (4) Highlight any gender-specific pathological and environmental risk factors associated with the planning or completion of mass shooting, spree killing, or terrorist attack events.

In terms of objective (1), discussion relating to female involvement in either solo or partnered mass shooting events is difficult based on the studies identified. The gap in literature available to quantitively assess this demographic has led to investigation of female mass shooters to be reliant on news media reports and case study reviews. Noted during the review was that in recent years, several mass shootings completed by females have taken place (e.g., Nasim Aghdam case, 2018; Snochia Moseley case, 2018; Dorothy Dutiel case, 2016; Amy Bishop case 2010; Latina Williams case, 2008), yet the only case study review available for scrutiny was by Katsavdakis and colleagues (2011). While comparison between cases is difficult and presents issues with reliability; largely due to the sensationalist and potentially inaccurate nature of information when accessed via mainstream media channels, several comparable characteristics between female mass shooting events in the press and in the study available were noted.

Firstly, target and focus of grievance. Following review of Katsavdakis and colleagues (2011) case study, in addition to recent cases in the press (e.g., Nasim Aghdam; Snochia Moseley), the target of mass shooting attacks completed by females show a higher proportion; relative to their occurrence compared to male counterparts, to be focussed on either current or prior places of work. While mass shooting by females only accounts for $4 \%$ of all cases, The Department of Justice Mass Shooting Database | The Violence Project, (2020) highlights such events were aimed at previous or current employers at a disproportionately higher rate. Several recent cases that showcase this include a mass shooting events completed by Nasim Aghdam in 2018, Snochia Moseley in 2018, and the case discussed by Katsavdakis and colleagues (2011). Although peer review analysis of these events is yet to be completed, discussion of such events is deemed at paramount in establishing environmental precipitating factors involved in triggering such violence among females. Perhaps with reference to Cunningham (2007) who outlined 'six deficiencies in counter-terror', the lack in academic interest to delve into such incidents among females when compared males, highlights that across subsets of terrorism that misconceptions surrounding the risk females present is an obstructive factor limiting meaningful analysis.

Secondly, and leading on from the above mention issue of misconception relating to risk, contact with law enforcement directly before the attack is present in the above noted cases. For example, in the case of Nasim Aghdam, concerned family members contacted police following Aghdams increasingly agitated behaviour and verbal disclosure of wanting to take revenge on YouTube HQ for demonetising her videos (Choi, 2018). Although police did track down and find the subject in her car across states lines 25 miles away from YouTube HQ, police deemed that there was no risk of violence 
and left (Allen, 2018). Shortly after this meeting, the attack was carried out. Similarly, in the case discussed by Katsavdakis and colleagues (2011), concerns were raised by the family and friends regarding the increasingly delusional beliefs and anger directed towards the subject's previous place of work. Despite recent hospitalisation and contact with law enforcement following these reports made by the family, the subject was able to obtain a firearm and complete the attack on her previous employer.

Finally, evidence of fixation, planning and leakage can be noted in all the above referenced cases and can be aligned to threat assessment models of mass shooting warning behaviours for example by Meloy and colleagues (2012). Further, in the Nasim Aghdam case, continuation of rumination, increasing aggressive presentation and verbal disclosure of aggressive intent prior to purchasing a weapon and undertaking shooting practice at a range; in addition to researching how to travel to YouTube HQ follows the depicted pathway to violence and mirrors the warning behaviours outlined by Meloy and colleagues. Similarly, in the case discussed by Katsavdakis and colleagues (2011), the authors discuss the gradual decline in Ms T's mental state, with perpetuating paranoid delusions and subsequent writing suggesting violent intent. Also discussed was the level of planning required to breach the security levels present within the US postal service, where the subject previously worked, noting that despite not being employed by the service for four years, that the planning may have been undertaken for the duration of the time since her employment terminated. Again, this case highlights a consistent pattern associated with mass shooting attacks, underlining that there are warning behaviours, particularly verbal and/or written intent prior to completing the attacks that went unnoticed.

In relation to objective (2), many of the studies identified explored female involvement in terrorist organisations, enabling a deeper exploration of this demographic. From evaluating the studies available for this review, it has become apparent that characteristics of females allied to terrorist organisations vary relative to the organisation one is involved with; moreover it appears that there is a complex variability between female and male terrorists' dependant on both ideology and descriptive characteristics; such as age, role in organisation, extent of extremist beliefs and impact of relational ties. Despite this, results of the comparative studies available do have coherence and show support for one another in consistently highlighting such differences (e.g., Jacques \& Taylor, 2012; Gonzalez et al., 2014; Brugh et al., 2019). While there is a general consensus among descriptive characteristics, the motivational variables and precipitating factors hypothesised as forming the catalyst to female involvement are less quantitatively studied and thus understood. For example, several of the available studies highlight that extremist beliefs are non-present in females who plan, attempted or complete suicide bombings tied to radical Islamism (Jacques \& Taylor, 2009; Jacques and Taylor, 2012). Similarly, females involved in right-wing terror organisations have similar rates of extremist beliefs when compared to males from the same group, however Ganzalez and colleagues (2014) notes that among far-right organisation within the US, males often have coexisting extremist Christian beliefs and females do not. This is in contrast to females who are involved with environmental and animal rights 
extremist organisations, where all of the females identified in attempted or completed attacks held extremist views and were ideologically driven, at an equal prevalence to males allied to the same cause.

As such, without the extremist views perceived to drive involvement in such organisations, several studies (e.g., Cunningham, 2007; Sawicki, 2016; Wickham et al., 2020) have debated the reasoning behind females becoming involved in such activities. Again, following review of the currently available data, it appears that motivations varied widely based on the organisation and societal conditions that females lived in prior to involvement. For example, Wickham and colleagues (2020) notes that females in far-right extremist organisations were disproportionately from lowersocioeconomic backgrounds, did not have a secondary or tertiary level of education, had experienced poverty; in some cases, homelessness, and had experienced divorce or a breakdown in their relationships prior to involvement. As such, this adds weight for the view that relative deprivation can in part mobilise some women to join and actively participate in extremist organisations (Jacques \& Taylor, 2012). In contrast, females allied to extremist Islamist terror groups were more likely to have tertiary level education and close relational ties to the organisation. As such, the authors note that relational ties to extremist organisations is paramount to female affiliation and subsequent violent attacks among this group, rather than the desire for education or financial reward. Such views are also supported by previous research, for example in Gonzalez and colleagues (2014) who also found that relationships formed the catalyst for female involvement in terror plots, particularly among females involved with jihadi-inspired violence with tertiary level education.

Similarly, the results of Wickham and colleagues (2020) study highlights and offers support for previous research (e.g., Cunningham, 2007) that stipulates inaccuracy in the view that females involved in Islamic extremism are coerced and without agency, or are often manipulated into joining such causes out of promise of education and financial reward. Again, this underlines assertions that females involved with terrorism are surrounded by unfounded misconceptions, arguably based on western interpretation of female roles within Islamic extremist organisations. Furthermore, this understanding highlights the modality of terrorist organisations who increasingly use such misconceptions as a strategic advantage, for example by recruiting females to complete suicide bombings at an equal level to males, in addition to having females take roles making explosive devices (Cunningham, 2007; Wickham et al., 2020). This further aids in the understanding as to how foreign fighting by females is significantly more successful than when attempted by male counterparts (Brugh et al., 2019).

The third objective for the present study was to highlight any female specific pathology present in women who have completed or conspired to complete acts of extreme violence, and while there was ample research evaluating descriptive variables in relation to female terrorists; such as age, employment history, presence of criminal record and marital status, there was no formal assessment data present to investigate factors relating to psychopathology. Again, case study material utilising interview data had been attempted to shed light on the psychology of the females discussed; and despite efforts to 
triangulate information gathered in relation to this (e.g., Jacques and Taylor, 2012; Felthous et al., 2019), the lack in formal assessment is problematic from an academic perspective.

Despite the lack in formal assessment, two of the papers reviewed did discuss the mental state of the female subject in question. In Felthous and colleagues (2019) the case studies of female bombers were evaluated by reviewing interview data from family members. Throughout the review, the authors note that the presence of symptoms exhibited by female bombers; according to family members, align with conditions such as major depression, delusional disorders and post-traumatic stress disorder. While such assertions can be somewhat supported by other case studies, for example in Katsavdakis and colleagues (2011) where the subject had a formal diagnosis of paranoid schizophrenia, there can be no reliable way of comparison without adequate testing. Additionally, as per the case studies reviewed by Felthous and colleagues (2019), the presence of significant life events; such as the loss of a child or spouse and the breakup of a marriage were present in the months prior to suicide bombing attacks, such as in the case of Idris Wafa. As such, it could be argued that rather than meeting the clinical threshold for certain psychiatric conditions, the suicide attacks were carried out due to environmental stressors relating to familial relationships and fear of cultural reprimand; for example, in the event of marital breakdown. As noted in Wickham and colleagues (2020), suicide bombings as a means to escape the negative connotations associated with such events have been utilised at a recruitment technique in organisations such as Al-Qaeda. Moreover, this observation can in part be extended to the remit familial ties in relation to motivation, as previous understanding notes that close relational ties form a catalyst to female involvement in extremist organisations, however such events may highlight that broken familial ties can be equally as powerful to motivate some women.

As mentioned above briefly, of all the studies reviewed, only one by Katsavdakis and colleagues (2011) discussed a case whereby the female assailant had a formal diagnosis: of paranoid schizophrenia. While the subject, named throughout as Ms T, did suffer from a severe mental disorder, the catalyst for the attack appeared to be following years of rumination and planning following her dismissal from her place of work. As noted in previous research relating to male mass shooters, past grievances appear to aggravate and give rise to extremely violent behaviour amongst individuals with severe delusional disorders such as paranoid schizophrenia (Lankford \& Hakim, 2011). While the presence of any other condition was absent in the case of Ms T, the pathway to violence in addition to her medical condition appear to follow the same trajectory as with male mass shooters. Additionally, the authors note that such cases can aid in disputing that the risk of violence amongst such individuals decreases over time as, conversely in cases where mass shootings have taken place amongst those with delusion disorders, many months even years can pass between the event causing grievance and the completed attack (Duwe, 2006). It could be argued that having such conditions enables a prolonged period of rumination and planning, increasing the focus and paranoia of such individuals rather than to pacify any threat. Moreover, it adds to the growing body of research (e.g., Lankford \& Hakim, 2011) 
that showcases that mass shooters do not 'snap', their attacks are not impulsive, but are extensively planned and carried out with precision despite the presence of mental disorder.

Finally, objective (4) of the review aimed to identify any gender specific environmental enablers precipitating involvement with mass shooting or terrorist attacks. The literature empirically investigating such variables amongst female mass shooters was scant and therefor comparison relied upon cases study material; for example, in Katsavdakis and colleagues (2011) and previously evaluated research on male mass shooters (e.g., Newman et al., 2004; Newman \& Fox, 2009; Lankman \& Hakim, 2011) in addition to accessing data from The Department of Justice Mass Shooting Database | The Violence Project, (2020). As such, deductions regarding the pathway to violence was attempted and while similarities between genders was observed on review of the current literature and news media articles; for example, in relation to planning and the presence of mental disorder, only one difference specific to females was recognised. As mentioned earlier, a higher proportion relative to the incidence of females completing mass shooting events are targeted at previous or current employers when compared to the male demographic. This finding highlights a potential avenue for further exploration, as the catalyst for female grievance precipitating a mass shooting attacks is most often attributed to injustices perceived in the workplace.

Although research analysing differences between male and female mass shooters was unobtainable, research empirically evaluating gender differences amongst those in terrorist organisations was more readily available to review. While the current research focusses on descriptive demographics; such as age of radicalisation, criminal history and marital status, much of the studies consistently offer support for the differences observed. For example in Jacques and Taylor (2012) the comparison of 222 female and 269 male terrorists uncovered that females were significantly less likely to be employed prior to radicalisation or attempting/completing attacks, were less likely to be religious converts or exhibit extremist beliefs, were less likely to be immigrants and more likely to be widowed or divorced. As such, these findings add weight to the notion that female suicide bombers are often recruited following significant life events such as marital breakdown or being widowed (Felthous et al., 2019). Also found was that $84 \%$ of the sample were aged between 18-35, and while the ages of genders did not differ significantly at the time of attack, the age of radicalisation was predominantly after 1990 for females, highlighting that efforts to reduce the rate of radicalisation could be focused amongst the younger demographic particularly amongst females.

Also important to note is that the study found low levels of immigration amongst the females who had completed or conspired in terror plots, offering little support for the current perception that isolation as a result of migration increases the capacity for radicalisation and subsequent violence amongst female terrorists (Gonzalez et al., 2014). Further, findings of the study also note that while there is a perception that female terrorists have lower levels of education and higher levels of economic hardship compared to male counterparts, there was no significant difference between genders based on these two variables in all groups aside for far-right groups within the United States. As such, this finding 
again disputes current perceptions that females are most often coerced into extremism at the promise of education and financial reward (Wickham et al., 2020) and add weight for the argument that females in terrorist organisations do have personal agency.

Such findings were more recently mirrored by Brugh and colleagues (2019) who also found that the age, educational level and economic status of individuals associated with terrorist plots did not differ significantly by gender. However, some key differences were observed in relation to prior criminal history and attempts of foreign fighting; including the success of such attempts at foreign fighting. It was found that females were significantly less likely to have a prior criminal history compared to males, were more likely to attempt foreign fighting, and were more likely to be successful on their first attempt during such attacks. As such, it could be argued that female terrorism-related outcomes are in part aided in their level of success due to continued underestimation of the risk posed by radicalised women (Jacques \& Taylor, 2012). As stipulated by Cunningham (2007), the interpretation that female terrorists are a rarity, often take passive roles within organisations and are not entrusted by organisations to take fighting roles have enabled a tactical advantage to such organisations in terms of their success in terrorist attack plots. This underscores a deficiency in counter terror strategy that requires addressing to prevent future attacks.

\section{Limitations}

One of the potential limitations with this review is that some relevant articles were not identified during the search. The risk of this was minimised as much as possible by screening the reference section of relevant reviews and theoretical papers (which were identified in the search of the databases) for any potentially relevant articles that may have been missed. In addition, numerous permutations of the search criteria that were entered into the databases were also entered into 'GoogleScholar'.

Additionally, the third objective of the current study; to examine the pathology of females involved in acts of extreme violence, has been acknowledged as being potentially problematic. It could be considered that evaluating the pathology of females involved in acts of extreme violence as whole, rather than in decreet groups based on individual types of events may distort findings and limit the capacity to identify 'event specific' pathology within the demographic. However, due to the current research evaluating pathology among female terrorists and mass shooters being scant, the decision to examine this as a whole was deemed necessary in order to discuss female propensity for violence in acts or events that cause a greater risk to the public. Despite this, further research will be needed to aid in developing our understanding and clarifying potential differences.

Clinical and Legal Implications and Recommendations 
Despite the present review finding several papers that empirically explored characteristic data of females involved within terrorist organisations, there appears to be a large gap in literature quantitively assessing the rates of psychopathological variables amongst this demographic. When narrowing the lens further onto female mass shooters, empirical literature investigating even characteristic variables continues to evade the academic remit. Arguably this obstruction to our current understanding of female perpetrated violence, both in an organised terror and a mass shooter/murder capacity, limits the ability to meaningfully evaluate whether previous models assessing risk amongst mass shooters; such as in Meloy and colleagues (2012) is valid across genders. As result of this finding, it is emphasised that continued efforts to establish psychological precipitating factors amongst females be addressed.

Additionally, several of the reviewed papers discussed myths and misconceptions relating to female participation in terrorist organisations, highlighting that collectively perceptions informing counterterror strategies should be evaluated with a new understanding that organisations; particularly those allied to jihadi-inspired extremism, are adapting and moving away from traditionally understood hierarchical structures (Wickham et al., 2020). As such, confronting the identified 'deficiencies' within counterterror could enable a greater success at preventing attacks completed by females, particularly in relation to foreign fighting, suicide bombings and in the making of explosive devices (Cunningham, 2007).

Finally, current literature has highlighted that the age of radicalisation amongst females across both jihadi-inspired, right-wing and far-left extremist organisations is decreasing, with many new recruits being born after 1990 (Jacques \& Taylor 2012). This finding aids in identifying a point of entry to minimise the chance of radicalisation, through targeted educational training and anti-radicalisation programmes intervening in at risk groups at the correct time. However, further exploration will be necessary to identify specific risk factors prior to radicalisation in such groups.

\section{Conclusion}

Although the literature obtained enabled a synthesis of descriptive characteristics amongst females involved with organised terror; and a comparison of such findings with the male demographic, the persisting gap in literature investigating psychopathological factors limited the capacity to identify any additional risk increasing variables in this review. Despite theoretical discussion using triangulated case study material, further empirical research is deemed crucial in broadening our understanding of female completed acts of terror, in both a reliable an ecologically valid way. 


\section{References}

Allen, K. (2018). Family of alleged YouTube shooter warned police 'she might do something'. Retrieved from https://abcnews.go.com/US/family-alleged-youtube-shooter-warned-police/story?id=54224487

Björkqvist, K. (2018). Gender differences in aggression. Current Opinion in Psychology, 19, 39-42

Blee, K. (2005). Women and Organized Racial Terrorism in the United States. Studies In Conflict \& Terrorism, 28(5), 421-433. doi: 10.1080/10576100500180303

Brugh, C., Desmarais, S., Simons-Rudolph, J., \& Zottola, S. (2019). Gender in the Jihad: Characteristics and Outcomes Among Women and Men Involved in Jihadism-Inspired Terrorism. Journal of Threat Assessment and Management, 6(2), 76-92.

Campion, K. (2020). Women in the Extreme and Radical Right: Forms of Participation and Their Implications. Social Sciences, 9(9), 149.

Choi, D. (2018). "Father of the suspected YouTube shooter reportedly told police his daughter was 'angry' with the company, warned that she might travel to its office". Business Insider. Available at http://uk.businessinsider.com/nasim-aghdam-youtube-shooter-father-told-police-she-was-angry-2018$4 ? \mathrm{r}=\mathrm{US} \& \mathrm{IR}=\mathrm{T}$

Cruise, R. (2016). Enough with the Stereotypes: Representations of Women in Terrorist Organizations*. Social Science Quarterly, 97(1), 33-43. doi: 10.1111/ssqu.12250

Cunningham, K. (2007). Countering Female Terrorism. Studies in Conflict \& Terrorism, 30(2), pp. 113129.

Felthous, A., Samantarai, S., \& Mukhtar, A. (2019). Gender differences in combined homicide-suicide with consideration of female terrorist bombers. Behavioural Sciences \& The Law, 37(5).

Fox, J. A., \& Fridel, E. E. (2017). Gender differences in patterns and trends in US homicide, 19762015. Violence and gender, 4(2), 37-43.

Gonzalez, A., Freilich, J., Chermak, S. (2014). How women engage homegrown terrorism. Feminist Criminology, 9(4), pp.344-366.

Gurian, E. (2018). Offending, Adjudication, and Outcome Patterns of Solo Male, Solo Female, and Partnered Mass Murderers. International Journal of Offender Therapy \& Comparative Criminology, 62(7). doi: 28671002

Hamiliton, C. (2009). Review of Women and Terrorism: Female Activity in Domestic and International Terror Groups. Journal of Gender Studies, 18(2), pp. 202-213.

Jacques, K., \& Taylor, P. (2013). Myths and Realities of Female-Perpetrated Terrorism. Law \& Human Behaviour, 37(1), 35-44.

Jacques, K., Taylor, P. (2009). Female Terrorism: A Review. Terrorism and Political Violence, 21(3), pp. 499-515.

Katsavdakis, K., Meloy, R., \& White, S. (2011). A Female Mass Murder. Journal of Forensic Sciences, $56(3)$. 
Lankford, A., \& Hakim, N. (2011). From Columbine to Palestine: A comparative analysis of rampage shooters in the USA and volunteer suicide bombers in the Middle East. Aggression and Violent Behavior, 16, 98-107.

Madfis, E., \& Cohen, J. W. (2018). Female involvement in school rampage plots. Violence and gender, $5(2), 81-86$.

Mass Shooting Database Locations | The Violence Project. (2020). Retrieved 25 September 2020, from https://www.theviolenceproject.org/mass-shooter-database/

Messing, J., \& Heeren, J. (2004). Another Side of Multiple Murder. Homicide Studies, 8(2), 123-158. doi: $10.1177 / 1088767903262446$

Moher, D., Liberati, A., Tetzlaff, J., \& Altman, D. (2009). Preferred reporting items for systematic reviews and meta-analyses: The PRISMA Statement. BMJ, 339(Jul 21 1), b2535-b2535. doi: 10.1136/bmj.b2535

Nacos, B. (2005). The Portrayal of Female Terrorists in the Media: Similar Framing Patterns in the News Coverage of Women in Politics and in Terrorism. Studies In Conflict \& Terrorism, 28(5), 435451. doi: 10.1080/10576100500180352

Newman, K. S., \& Fox, C. (2009). Repeat tragedy: Rampage shootings in American high school and college settings, 2002-2008. American Behavioral Scientist, 52, 1286-1308.

Newman, K. S., Fox, C., Roth, W., Mehta, J., \& Harding, D. (2004). Rampage: The social roots of school shootings. New York, NY: Basic Books.

Paul, K. (2019). Making a Terrorist: Psychosocial risk factors in the recruitment of female suicidehomicide bombers. The Sciences and Engineering, 80(2).

Reid Meloy, J., Hoffmann, J., Guldimann, A., \& James, D. (2012). The role of warning behaviors in threat assessment: An exploration and suggested typology. Behavioral sciences \& the law, 30(3), 256279.

Rodriguez-Spahia, D. (2019). Gender and Terrorism: A Homeland Security Perspective. Humanities and Social Sciences, 70(2).

Sawicki, J. (2016). Why Terrorists Use Female and Child Suicide Bombers. Retrieved 17 September 2020, from https://www.chausa.org/publications/health-progress/article/july-august-2016/whyterrorists-use-female-and-child-suicide-bombers

Wickham, B. M., Capezza, N. M., \& Stephenson, V. L. (2020). Misperceptions and motivations of the female terrorist: A Psychological Perspective. Journal of Aggression, Maltreatment and Trauma, 29(8), 953-968. 